\title{
ATZ (3-amino-1,2,4-triazole) injected into the fourth cerebral ventricle influences the Bezold-Jarisch reflex in conscious rats
}

\author{
Vitor E. Valenti,' Luiz Carlos de Abreu," Monica A. Sato," Celso Ferreira' \\ 'Universidade Federal de São Paulo (UNIFESP) - Departamento de Medicina, Disciplina de Cardiologia, São Paulo, São Paulo, Brazil. "Faculdade de \\ Medicina do ABC - Departamento de Morfologia e Fisiologia, Santo André, São Paulo, Brazil.
}

OBJECTIVES: Many studies have investigated the importance of oxidative stress on the cardiovascular system. In this study we evaluated the effects of central catalase inhibition on cardiopulmonary reflex in conscious Wistar rats.

METHODS: Male Wistar rats were implanted with a stainless steel guide cannula in the fourth cerebral ventricle. The femoral artery and vein were cannulated for mean arterial pressure and heart rate measurement and for drug infusion, respectively. After basal mean arterial pressure and heart rate recordings, the cardiopulmonary reflex was tested with a dose of phenylbiguanide (PBG, $8 \mu \mathrm{g} / \mathrm{kg}$, bolus). Cardiopulmonary reflex was evaluated before and $\mu \mathrm{l} 15$ minutes after $1.0 \mu \mathrm{L}$ 3-amino-1,2,4-triazole (ATZ, $0.01 \mathrm{~g} / 100 \mu \mathrm{L}) 0.01 \mathrm{~g} / 100 \mu \mathrm{L}$ ) injection into the fourth cerebral ventricle. Vehicle treatment did not change cardiopulmonary reflex responses.

RESULTS: Central ATZ significantly increased hypotensive responses without influencing the bradycardic reflex.

CONCLUSION: ATZ injected into the fourth cerebral ventricle increases sympathetic inhibition but does not change the parasympathetic component of the cardiopulmonary reflex in conscious Wistar rats.

KEYWORDS: Reflex; Oxidative Stress; Catalase; Medulla Oblongata; Cardiovascular System.

Valenti VE, Abreu LC, Sato MA, Ferreira C. ATZ (3-amino-1,2,4-triazole) RATSinjected into the fourth cerebral ventricle influences the Bezold-Jarisch reflex in conscious rats. Clinics. 2010;65(12):1339-1343.

Received for publication on July 23, 2010; First review completed on August 16, 2010; Accepted for publication on September 8 , 2010

E-mail: valenti@unifesp.br

Tel.: $55115572-5462$

\section{INTRODUCTION}

Reactive oxygen species (ROS), such as superoxide anions $\left(\mathrm{SO}_{2}{ }^{-}\right)$and hydrogen peroxide $\left(\mathrm{H}_{2} \mathrm{O}_{2}\right)$, once thought only to be harmful byproducts of oxidative metabolism, are now recognized as critical second messengers in a wide range of physiological processes. ${ }^{1-4}$ ROS are the result of incomplete reduction of oxygen to $\mathrm{O}_{2}{ }^{-}$, which is spontaneously or enzymatically dismutated to $\mathrm{H}_{2} \mathrm{O}_{2}$ by superoxide dismutase (SOD). $\mathrm{H}_{2} \mathrm{O}_{2}$ is transformed to $\mathrm{H}_{2} \mathrm{O}$ and $\mathrm{O}_{2}$ under catalase activity. ${ }^{5}$ 3-Amino-1,2,4-triazole (ATZ) is a heterocyclic organic compound that consists of a 1,2,4-triazole substituted with an amino group. ATZ is a competitive inhibitor of the product of the HIS3 gene, imidazoleglycerolphosphate dehydratase. Imidazoleglycerol-phosphate dehydratase is an enzyme catalyzing the sixth step of histidine production. This drug also inhibits catalase activity, thus increasing endogenous $\mathrm{H}_{2} \mathrm{O}_{2}{ }^{5}$

Copyright (c) 2010 CLINICS - This is an Open Access article distributed under the terms of the Creative Commons Attribution Non-Commercial License (http:// creativecommons.org/licenses/by-nc/3.0/) which permits unrestricted noncommercial use, distribution, and reproduction in any medium, provided the original work is properly cited.
Previously, von Bezold and Hirt observed that an intravenous injection of veratrum alkaloids caused a decrease in blood pressure and heart rate, which was then named the Bezold-Jarisch reflex or cardiopulmonary reflex. ${ }^{6}$ Chemical activation of the cardiopulmonary afferent endings with phenylbiguanide (PBG, 5-HT3 agonist) is a pharmacological approach that has been used by different laboratories to induce the cardiopulmonary reflex. This approach has been considered to be a valid index for the evaluation of the cardiopulmonary reflex. ${ }^{7}$ The activity of the sympathetic and parasympathetic systems, which are both involved in the cardiopulmonary reflex, is under the control of a medullary circuitry comprising the nucleus of the solitary tract (NTS), rostral (RVLM) and caudal ventrolateral medulla (CVLM) and the nucleus ambiguous. Drug injection into the fourth cerebral ventricle (V4) may easily reach structures surrounding the ventricular system such as the area postrema, NTS, CVLM, RVLM and the dorsal motor nucleus of the vagus. ${ }^{8}$

Previous studies indicated that ROS are also related to impaired baroreflex. ${ }^{9,10}$ It was found that increased cholesterol levels were associated with baroreflex gain $(\Delta H R /$ $\triangle \mathrm{MAP}$ ) dysfunction and an imbalance between oxidant and antioxidant forces. ${ }^{10}$ However, to the best of our knowledge, no previous study has demonstrated the effects of ATZ, a 
catalase inhibitor drug, injected into central areas involved in cardiovascular reflex. Therefore, we investigated the effects of central ATZ on the cardiopulmonary reflex in conscious Wistar rats.

\section{METHOD}

\section{Animals}

The experiments were performed in Wistar rats $(n=15$, 300-400 g). Rats were housed individually in plastic cages under standard laboratory conditions. They were kept under a 12-h light/dark cycle (lights on at 06:30 h) and had free access to food and water. Housing conditions and experimental procedures were approved by our institution's Animal Ethics Committee. Efforts were made to minimize the number of animals used.

\section{Surgical Preparation}

Five days before the experiment, the rats were anesthetized with ketamine (50 mg/ $\mathrm{kg}$ i.p.) and xylazine $(50 \mathrm{mg} / \mathrm{kg}$ i.m.). ${ }^{11,12}$ After scalp anesthesia with $2 \%$ lidocaine, the skull was exposed and stainless steel guide cannulas (26 G) were implanted into the V4 $1 \mathrm{~mm}$ above the injection site using a stereotaxic apparatus (David Kopf Instruments, USA). Stereotaxic coordinates for cannula implantation into the V4 were: AP, $-12 \mathrm{~mm}$ from the bregma; $\mathrm{L}, 0 \mathrm{~mm}$ from the medial suture; $\mathrm{V},-6.1$ to $6.4 \mathrm{~mm}$ from the skull. ${ }^{13}$ Cannulas were fixed to the skull with dental cement and one metal screw.

One day before the experiments, the rats were anesthetized with ketamine (50 mg/ kg i.p.) and xylazine $(50 \mathrm{mg} / \mathrm{kg}$ i.m.) and a catheter was inserted into the abdominal aorta through the femoral artery for blood pressure and heart rate recording. Another catheter was inserted into the femoral vein for drug administration. Catheters were made of 4-cm segments of PE-10 polyethylene (Clay Adams, USA) heat bound to a 13-cm segment of PE-50. The catheters were tunneled under the skin and exteriorized at the animal's dorsum. ${ }^{11,12,14}$

\section{Arterial pressure and heart rate recording}

After surgery, the animals were kept in individual cages, which were used to transport them to the experimental room. Animals were allowed 60 minutes to adapt to the conditions of the experimental room, such as sound and illumination, before starting blood pressure and heart rate recording. The experimental room was acoustically isolated and had constant background noise produced by an air exhauster. At least another 20-minute period was allowed before beginning experiments. Pulsatile arterial pressure of freely moving animals was recorded using an HP-7754A preamplifier (Hewlett Packard, USA) and an acquisition board (MP100A, Biopac Systems Inc, USA) connected to a computer. Mean arterial pressure (MAP) and heart rate (HR) values were derived from the pulsatile arterial pressure (PAP) recordings and processed on-line. ${ }^{15}$ No signs of pain or discomfort were observed.

\section{Cardiopulmonary reflex activation}

Animals were connected to the acquisition system and allowed to recover from manipulation stress for at least 30 minutes. When MAP and HR were stable, 20-30 minutes baseline.were recorded for the HR and MAP baselines. The cardiopulmonary reflex was evaluated through i.v. bolus injection of phenylbiguanide (PBG, $8 \mu \mathrm{g} / \mathrm{kg}$ ). Chemical activation of the cardiopulmonary afferent endings with PBG is a pharmacological approach that has been used by different laboratories to induce the cardiopulmonary reflex. This approach has been considered to be a valid index for the evaluation of the cardiopulmonary reflex. ${ }^{7}$

\section{Injections into the V4}

Injections into the V4 were made with $10-\mu \mathrm{L}$ Hamilton syringes connected by polyethylene tubing (PE-10) to an injector needle. The injector, when completely inserted, protruded $2 \mathrm{~mm}$ beyond the tip of the guide cannula. Injections into the V4 were $1.0 \mu \mathrm{L}$ for about $5-10 \mathrm{~s}^{16}$

\section{Experimental procedures}

Central catalase activity was inhibited by injection of 3amino-1,2,4-triazole (ATZ, $0.01 \mathrm{~g} / 100 \mu \mathrm{L}$ - catalase inhibitor) into the V4. To verify cardiopulmonary reflex after central catalase inhibition we tested cardiopulmonary reflex before (control) and 15 minutes after ATZ administration into the V4.

\section{Histology}

In order to confirm the placement of the injection needle, at the end of the experiments the animals were anesthetized with urethane (1.25 g/ kg i.p.), and $200 \mathrm{~nL}$ of $1 \%$ Evan's blue dye was injected into the V4 as a marker of the injection site. The chest was surgically opened, the descending aorta occluded, the right atrium severed and the brain perfused with $10 \%$ formalin through the left ventricle. The brains were post fixed for $24 \mathrm{~h}$ at $4{ }^{\circ} \mathrm{C}$, and $40-\mu \mathrm{m}$ sections were cut in a cryostat (model CM 1900, Leica, Germany). Brain sections were stained with $1 \%$ neutral red. The actual placement of the injection needles was verified in serial sections. ${ }^{16}$

\section{Statistical Analysis}

The results are reported as means \pm standard error of means. In order to compare variables (bradycardia and hypotension induced by PBG) before and 15 minutes after ATZ test.administration, we used the paired Student's t-test. Analyses of variance (ANOVA) for repeated measures followed by the Tukey post test were used for comparisons of MAP and HR before, 5, 15, 30, and 60 minutes after ATZ treatment. Differences were considered significant when the probability of a type I error was less than $5 \%(p<0.05)$.

\section{RESULTS}

\section{Histology}

Fig. 1 is a photomicrograph showing the typical sites of the injections into the V4 in one rat representative of the rats used in our study. According to Paxinos and Watson, ${ }^{13}$ these coronal sections are located approximately $13 \mathrm{~mm}$ caudal to bregma.

\section{Effects of ATZ on Basal MAP and HR}

The vehicle-treated group did not present significant changes in relation to baseline MAP (Table 1). Conversely, we observed that injections of ATZ into the V4 produced a significant $(\mathrm{p}<0.05)$ increase in basal MAP in conscious Wistar rats 60 minutes after injection (Table 1 ). The results presented in Table 1 are modest and the degree of the 


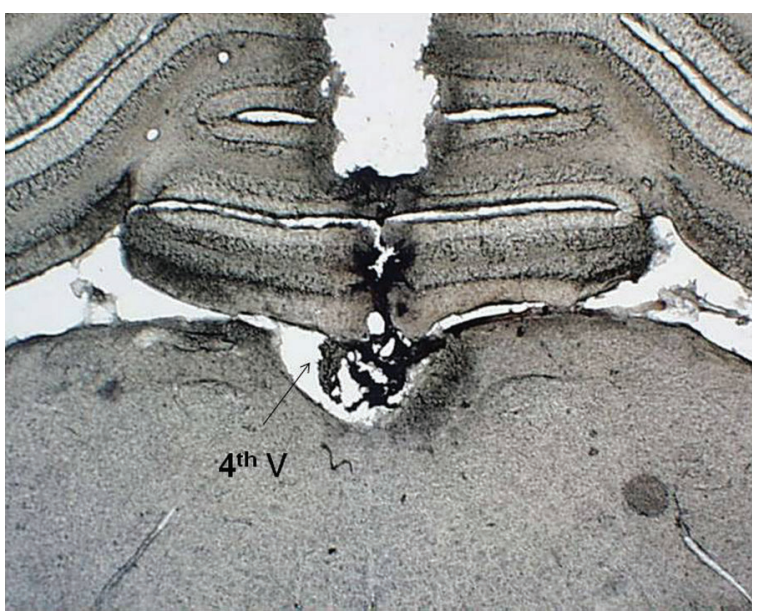

Figure 1 - Histological image of a rat brain coronal slice showing the medulla and cerebellum ( $\sim 13 \mathrm{~mm}$ caudal to bregma). V4: fourth cerebral ventricle.

alteration is not higher than the difference between vehicle and ATZ groups at 60 minutes: ATZ 106(113-119 mmHg or $5.0 \%$ ) vs vehicle (101-106 mmHg or $5.1 \%$ ) groups.

Basal HR was not significantly changed after vehicle injection into the V4 of Wistar rats (Table 1). On the other hand, central catalase inhibition significantly $(p<0.05)$ increased basal HR in the ATZ-treated group during the first 15 minutes (Table 1).

\section{Effects of ATZ on Cardiopulmonary Reflex}

The PBG dose of $8 \mu \mathrm{g} / \mathrm{kg}$ elicited a biphasic response with initial bradycardia and hypotension in both groups. In the ATZ-treated group the hypotension was significantly increased $(p=0.012)$ after catalase inhibition into the V4 (Fig. 2B). However, no significant alteration was observed regarding bradycardic reflex elicited by i.v. PBG $(p=0.2522)$. Bradycardic responses to i.v. PBG and the hypotension elicited by i.v. PBG were not significantly influenced by vehicle injection into the V4 (Fig. 2A).

\section{DISCUSSION}

In this study we reported that injections of ATZ, a catalase inhibitor, into the V4 significantly increased basal MAP and HR. Moreover, it also increased hypotensive responses to cardiopulmonary reflex activation with i.v. PBG but not the bradycardic reflex. On the other hand, in rats treated with vehicle (saline $0.9 \%$ ) we observed no significant changes regarding baseline $\mathrm{MAP}$ and $\mathrm{HR}$ and sympathetic and parasympathetic components of the Bezold-Jarisch reflex (cardiopulmonary reflex). The lack of any change in the vehicles groups is consistent with this assumption. Owing to the anatomical extent of the V4, an effect on only one neuronal group is not an easy accomplishment; nevertheless, studiesprevious studies have suggested a preference for parasympathetic whichsystems modulateswhich modulate HR, such as the nucleus ambiguous and dorsal motor nucleus of the vagus, which receive glutamathergic projections from the nucleus tractus solitarius. ${ }^{8}$

We noted that baseline MAP and HR were enhanced after catalase inhibition into the V4. Cardoso et al. ${ }^{16}$ showed that exogenous $\mathrm{H}_{2} \mathrm{O}_{2}$ caused pressor dose-dependent responses in conscious Wistar rats, and peripheral blockade of adrenoceptors $\alpha_{1}$-adrenoceptors with prazosin abolished those responses elicited by exogenous $\mathrm{H}_{2} \mathrm{O}_{2}$, suggesting that increased ROS in the brainstem stimulate sympathetic discharges causing vasoconstriction and an increase in arterial pressure. Considering that ATZ is a catalase inhibitor and consequently increases endogenous $\mathrm{H} 2 \mathrm{O} 2,17$ we expected that ATZ injected into the V4 would cause the same responses observed in the research of Cardoso et al; ${ }^{16}$ however, we did not report bradycardic responses. On the other hand, basal MAP was not similar between vehicle and ATZ-treated groups before treatment $(101 \mathrm{mmHg}$ vs $113 \mathrm{mmHg}$, respectively). Thus, we should be careful of interpreting this change observed in MAP after central ATZ treatment.

Based on our findings, increased basal HR during the first 15 minutes after ATZ injection into the V4 indicates sympathetic overactivity. Furthermore, antioxidant treatment ${ }^{18}$ in RVLM blunted the elevated $\mathrm{O}_{2}^{-}$and $\mathrm{H}_{2} \mathrm{O}_{2}$ in RVLM, leading to reduction in sympathetic vasomotor outflow and vasodepression in hypertensive animals. Thus, our findings are in agreement with the literature.

The hypotensive response to i.v. PBG represents sympathetic inhibition while bradycardic reflex response to the Bezold-Jarisch reflex indicates parasympathetic activation. ${ }^{19}$ Many previous studies have already shown the effects of oxidative stress on the cardiovascular reflex. Zanzinger and Czachurski $^{20}$ demonstrated that SOD injected into the RVLM decreased sympathetic nerve activity in swine. Several groups have now shown that ROS stimulate central sympathetic outflow. ${ }^{21,22}$ Campese et $\mathrm{al}^{22}$ provided evidence that the lack of low-density lipoprotein (LDL) receptor-enhanced cholesterol blood levels increased oxidative stress and impaired baroreflex sensitivity. Monahan et $\mathrm{al}^{23}$ supported the hypothesis that oxidative stress contributes to age-associated decreases in cardiovagal baroreflex sensitivity in healthy men. On the

Table 1 - Baseline level of mean arterial pressure (MAP) and heart rate (HR) in Wistar rats treated with vehicle (vehicle group: $\mathrm{N}=7$ ) and Wistar rats treated with $\mathrm{ATZ}$ (ATZ group: $\mathrm{N}=8$ ).

\begin{tabular}{|c|c|c|c|c|c|c|}
\hline Vehicle group & Variable & Control & 5 minutes & 15 minutes & 30 minutes & 60 minutes \\
\hline & MAP $(\mathrm{mmHg})$ & $101 \pm 3$ & $101.4 \pm 2$ & $100 \pm 1$ & $103 \pm 5$ & $106.2 \pm 4$ \\
\hline & HR (bpm) & $354 \pm 6$ & $343.7 \pm 5$ & $354.7 \pm 4.9$ & $365.9 \pm 5$ & $370 \pm 2$ \\
\hline \multirow[t]{3}{*}{ ATZ group } & Variable & Control & 5 minutes & 15 minutes & 30 minutes & 60 minutes \\
\hline & MAP $(\mathrm{mmHg})$ & $113.1 \pm 1.6$ & $123.2 \pm 1.1 *$ & $121.9 \pm 1.07$ * & $124.2 \pm 2.8 *$ & $118.75 \pm 0.2 *$ \\
\hline & HR (bpm) & $354.4 \pm 9$ & $433.75 \pm 12.6$ * & $437.25 \pm 14.7^{*}$ & $386.4 \pm 17.8$ & $347.74 \pm 11.5$ \\
\hline
\end{tabular}

Means \pm SEM.

${ }^{*} p<0.05$ : different from control. Means \pm SEM. 


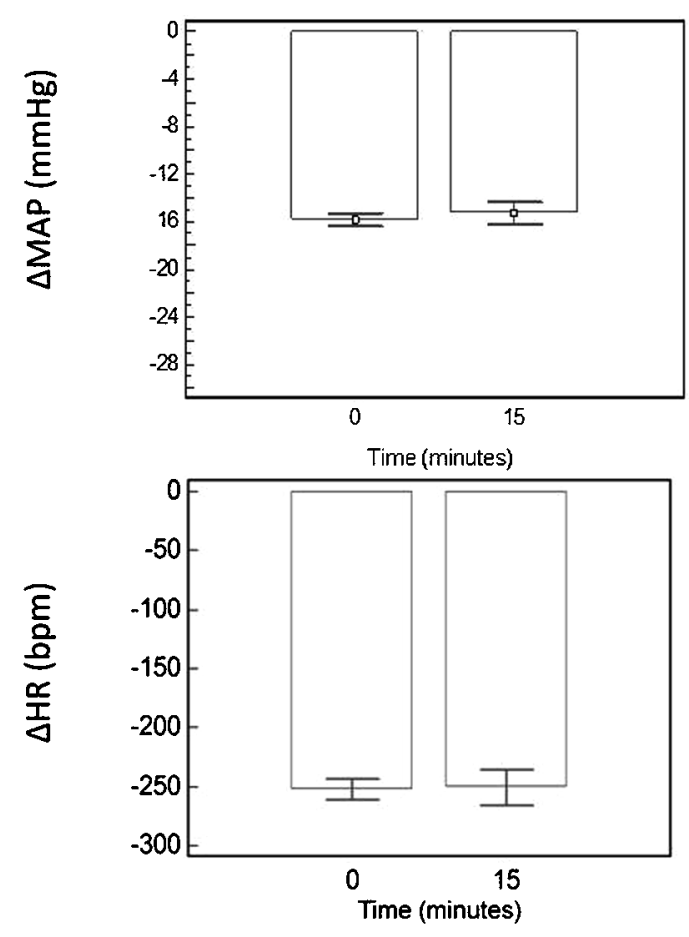

A
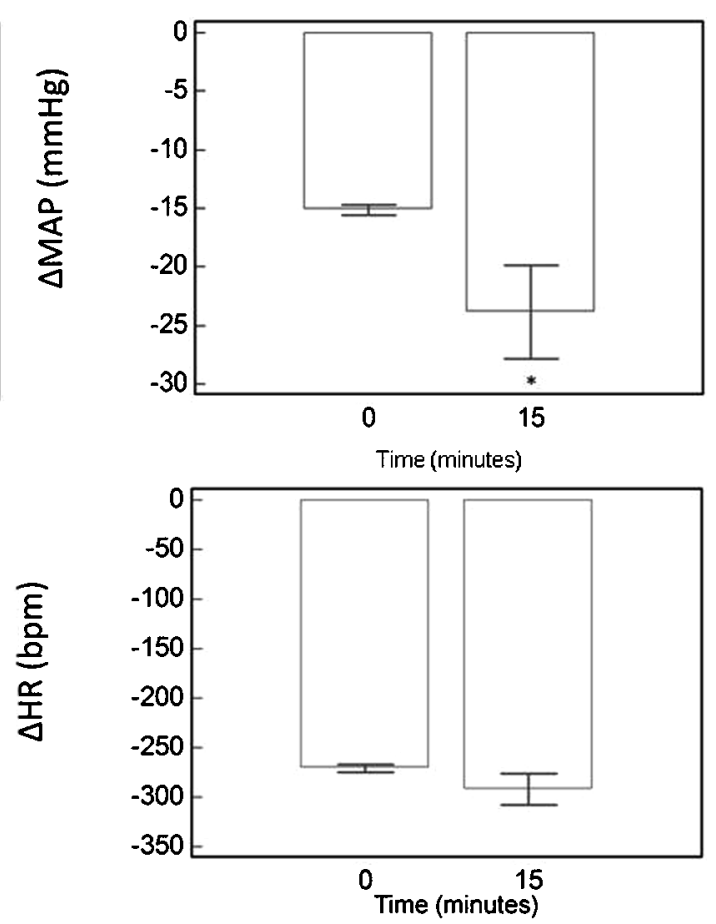

Figure 2 - Mean arterial pressure (MAP, $\mathrm{mmHg}$ ) and heart rate ( $\mathrm{HR}$, bpm) responses elicited by activation of the cardiopulmonary reflex by i.v. PBG injections in the vehicle-treated $(A, N=9)$ and groupATZ-treated groups $(B, N=8)$ before $(0$ minutes) and 15 minutes after ATZ administration into the V4. ${ }^{*} p<0.05$ : different from control (0 minutes).

other hand, Wright et $\mathrm{al}^{24}$ indicated that in male smokers, circulating antioxidants had no effect on baroceptor reflex function, and minor effects on the cardiovascular system were seen following acute fat and vitamin ingestion. To the best of our knowledge, no previous has study investigated the effects of ATZ injected into the V4 on cardiopulmonary reflex. Our data support the hypothesis that endogenous $\mathrm{H}_{2} \mathrm{O}_{2}$ in the regions surrounding the $\mathrm{V} 4$ is acutely associated with influencing the sympathetic inhibition component of the cardiopulmonary reflex in conscious rats.

As a main result, our data showed that catalase inhibition into the V4 increased hypotension responses to cardiopulmonary reflex activation without change bradycardic reflex. A recent study ${ }^{9}$ indicated that reduced oxidative stress due to exercise training is associated with attenuated cardiac sympathetic modulation and increased cardiopulmonary reflex in spontaneously hypertensive rats. Taken together, it is suggested that central ROS increases the hypotensive response. We believe that increased $\mathrm{H}_{2} \mathrm{O}_{2}$ caused by ATZ treatment into the V4 influences cardiopulmonary reflex due to a possible effect on the RVLM, since it controls the sympathetic discharges activating pre-ganglionic sympathetic neurons in the spinal cord. ${ }^{8}$ We suggest that ATZ increases endogenous $\mathrm{H}_{2} \mathrm{O}_{2}$ and decreases synaptic release of glutamate in RVLM neurons ${ }^{25}$ and as a consequence it increases baseline $\mathrm{HR}$ and the sympathetic inhibition component of the cardiopulmonary reflex, as observed in our study.

The dose of ATZ injected into the V4 used in our work was able to influence sympathetic inhibition during cardiopulmonary reflex activation. Previous investigations have used ATZ as a catalase inhibitor. ${ }^{26}$ Moreover, it was demonstrated that catalase activity can be significantly inhibited by the irreversible antagonist ATZ. ${ }^{26}$ Therefore, based on previous studies, we consider this drug as an effective catalase inhibitor.

We tested the cardiopulmonary reflex in conscious rats, since cardiorespiratory reflex activity is attenuated under anesthesia ${ }^{27}$ reducing the range of HR, which results in an analysis of a restricted portion of the cardiovascular response. Hence, we believe that our research provides reliable information regarding the effects of the catalase inhibitor ATZ, which increases endogenous $\mathrm{H}_{2} \mathrm{O}_{2}$, injected into the V4, on the sympathetic inhibition component of the Bezold-Jarisch reflex in Wistar rats. These data present relevant information; currently the cardiovascular reflex is largely studied in different models and strains of rats with the aim of preventing hypertension development in humans, because impaired cardiovascular reflex function is indicative of cardiovascular disease. ${ }^{28-}$ disease. ${ }^{28-31}$

One point from our investigation that should be addressed: we did not measure the concentration of $\mathrm{H}_{2} \mathrm{O}_{2}$ or other ROS inside the V4 before and after the injection of ATZ. It would significantly strengthen the impact of our results to show that $\mathrm{H}_{2} \mathrm{O}_{2}$ or some other ROS is actually altered in the $\mathrm{V} 4$ with this duration and level of treatment. Unfortunately, we did not measure endogenous $\mathrm{H}_{2} \mathrm{O}_{2}$ because of the lack of such equipment in our laboratory.

In conclusion, ATZ administration into the V4 increases the sympathetic inhibition response to i.v. PBG (hypotension) without significantly changing the parasympathetic component of the Bezol-Jarisch reflex (bradycardic response). We confirm the significance of ATZ at this particular dose on cardiopulmonary reflex. 


\section{REFERENCES}

1. Chattopadhyay A, Bandyopadhyay D. Vitamin E in the prevention of ischemic heart disease. Pharmacol Rep. 2006;58:179-87.

2. Karadeniz G, Acikgoz S, Tekin IO, Tascýlar O, Gun BD, Cömert M. Oxidized low-density-lipoprotein accumulation is associated with liver fibrosis in experimental cholestasis. Clinics. 2008;63:531-40, doi: 10.1590/ S1807-59322008000400020.

3. Budin SB, Othman F, Louis SR, Bakar MA, Das S, Mohamed J. The effects of palm oil tocotrienol-rich fraction supplementation on biochemical parameters, oxidative stress and the vascular wall of streptozotocininduced diabetic rats. Clinics. 44.2009;64:235-44.

4. Andraus W, Jukemura J, Dutra F, Bechara E, Cunha JE, Leite KR et al. Oxidative stress is enhanced by hypothermia imposed on ceruleininduced pancreatitis in rats. Clinics. 2007;62:483-90.

5. Joung JK, Ramm EI, Pabo CO. A bacterial two-hybrid selection system for studying protein-DNA and protein-protein interactions. Proc Natl Acad Sci U S A. 2000;97:7382-7, doi: 10.1073/pnas.110149297.

6. Jarisch A, Zotterman Y. Depressor reflexes from the heart. Acta Physiol Scand, 1948;16:31-35

7. Bissoli NS, Medeiros AR, Santos MC, Busato VC, Jarske RD, Abreu GR et al. Long-term treatment with supraphysiological doses of nandrolone decanoate reduces the sensitivity of Bezold-Jarisch reflex control of heart rate and blood pressure. Pharmacol Res. 2009;59:379-84, doi: 10.1016/j. phrs.2009.03.001.

8. Colombari E, Sato MA, Cravo SL, Bergamaschi CT, Campos RR, Lopes OU. Role of the medulla oblongata in hypertension. Hypertension. 2001;38:549-54.

9. Bertagnolli M, Schenkel PC, Campos C, Mostarda CT, Casarini DE, BellóKlein A, et al. Exercise training reduces sympathetic modulation on cardiovascular system and cardiac oxidative stress in spontaneously hypertensive rats. Am J Hypertens. 2008;21: 1188-93, doi: 10.1038/ajh.2008.270.

10. Campos C, Bertagnolli M, Evangelho J, Tusset C, Belló-Klein A, Irigoyen $\mathrm{MC}$ et al. Baroreflex sensitivity and oxidative stress in the LDL receptor knockout mice. Exp Toxicol Pathol. 2008;60: 329-35, doi: 10.1016/j.etp. 2008.02.005

11. Valenti VE, de Abreu LC, Imaizumi C, Petenusso M, Ferreira C. Strain differences in baroceptor reflex in adult Wistar Kyoto rats. Clinics. 2010;65:203-8, doi: 10.1590/S1807-59322010000200013.

12. Valenti VE, Ferreira C, Meneghini A, Ferreira M, Murad N, Ferreira Filho $\mathrm{C}$ et al. Evaluation of baroreflex function in Young spontaneous hypertensive rats. Arq Bras Cardiol. 2009;92:205-9, doi: 10.1590/S0066782X2009000300009

13. Paxinos G, Watson C. The rat brain in stereotaxic coordinates. 2nd ed. Sydney, NSW: Academic Press. 1997:75.

14. Farah Vde M, De Angelis K, Joaquim LF, Candido GO, Bernardes N, Fazan R Jr et al. Autonomic modulation of arterial pressure and heart rate variability in hypertensive diabetic rats. Clinics. 2007; 62:477-82.

15. Valenti VE, Imaizumi C, Abreu LC, Colombari E, Sato MA, Ferreira C. Intra-strain variations of baroreflex sensitivity in Young Wistar-Kyoto rats. Clin Invest Med. 2009;32: E251-E257, doi: 10.1172/JCI102734.

16. Cardoso LM, Colombari DSA, Menani JV, Chianca Jr DA, Colombari E. Cardiovascular responses produced by central injection of hydrogen peroxide in conscious rats. Brain Res Bull. 2006;71:37-44, doi: 10.1016/j. brainresbull.2006.07.013.

17. Ardanaz N, Beierwaltes WH, Pagano PJ. Distinct hydrogen peroxideinduced constriction in multiple mouse arteries: potential influence of vascular polarization. Pharmacol Rep. 2008;60:61-7.

18. Chan $\mathrm{SHH}$, Tai MH, Li CY, Chan JYH. Reduction in molecular synthesis or enzyme activity of superoxide dismutases and catalase contributes to oxidative stress and neurogenic hypertension in spontaneously hypertensive rats. Free Radic Biol Med. 2006;40:2028-39, doi: 10.1016/j. freeradbiomed.2006.01.032

19. Jordan D. Vagal control of the heart: central serotonergic (5-HT) mechanisms. Exp Physiol. 2005;90> 175-81.

20. Zanzinger J, Czachurski J. Chronic oxidative stress in the RVLM modulates sympathetic control of circulation in pigs. Pflugers Arch. 2009;439:489-494, doi: 10.1007/s004240050968.

21. Han Y, Zhang Y, Wang HJ, Gao XY, Wang W, Zhu GQ. Reactive oxygen species in paraventricular nucleus modulates cardiac sympathetic afferent reflex in rats. Brain Res. 2005;1058:82-90, doi: 10.1016/j.brainres. 2005.07.055.

22. Campese VM, Ye S, Zhong H, Yanamadala V, Ye Z, Chiu J: Reactive oxygen species stimulate central and peripheral sympathetic nervous system activity. Am J Physiol Heart Circ Physiol. 2004;287:H695-H703, doi: 10.1152 /ajpheart.00619.2003.

23. Monahan KD, Eskurza I, Seals DR. Ascorbic acid increases cardiovagal baroreflex sensitivity in healthy older men. Am J Physiol Heart Circ Physiol. 2004;3:H2113-H2117, doi: 10.1152/ajpheart.01054.2003.

24. Wright CI, Ruediger $\mathrm{H}$, Kroner CI, Janssen BJ, Draijer R. Acute autonomic effects of vitamins and fats in male smokers. Eur J Clin Nutr. 2009;63:246-52, doi: 10.1038/sj.ejcn.1602912.

25. Pellmar T. Electrophysiological correlates of peroxide damage in guinea pig hippocampus in vitro. Brain Res. 1986;364:377-81, doi: 10.1016/00068993(86)90851-6.

26. Perez-Vizcaino F, Duarte J, Jimenez R, Santos-Buelga C, Osuna A Antihypertensive effects of the flavonoid quercetin. Pharmacol Rep. 2009;61:67-75.

27. Fluckiger JP, Sonnay M, Boillat N, Atkinson J. Attenuation of the baroreceptor reflex by general anesthetic agents in the normotensive rat. Eur J Pharmacol. 1985;109:105-9, doi: 10.1016/0014-2999(85)90545-X

28. Zamo FS, Lacchini S, Mostarda C, Chiavegatto S, Silva IC, Oliveira EM et al. Hemodynamic, morphometric and autonomic patterns in hypertensive rats - Renin-Angiotensin system modulation. Clinics. 2010;65:8592, doi: 10.1590/S1807-59322010000100013.

29. Andrade AC, Cesena FH, Consolim-Colombo FM, Coimbra SR, Benjó $\mathrm{AM}$, Krieger EM et al. Short-term red wine consumption promotes differential effects on plasma levels of high-density lipoprotein cholesterol, sympathetic activity, and endothelial function in hypercholesterolemic, hypertensive, and healthy subjects. Clinics. 2009;64:435-42, doi: 10.1590/S1807-59322009000500011.

30. Vanderlei LC, Pastre CM, Freitas Júnior IF, Godoy MF. Geometric indexes of heart rate variability in obese and eutrophic children. Arq Bras Cardiol. 2010 Jul 2. pii: S0066-782X2010005000082. [Epub ahead of print].

31. Paschoal MA, Trevizan PF, Scodeler NF. Heart rate variability, blood lipids and physical capacity of obese and non-obese children. Arq Bras Cardiol. 2009;93:239-46, doi: 10.1590/S0066-782X2009000900007. 